\title{
Digital Directions \\ Staff development and training in the digital library environment
}

\author{
Nick Joint \\ Associate Senior Research Fellow, \\ Centre for Digital Library Research, \\ University of Strathclyde. \\ Email: n.c.joint@strath.ac.uk
}

\begin{abstract}
Traditional approaches to library training flourished in the period of hard copy collection building, when certain common generic skills, such as those of cataloguing and indexing, formed the bedrock of knowledge for many LIS professionals. The skills required in the digital library context are more heterogeneous, fluid and fastchanging. They require a different training philosophy, one more closely identified with a 'constructivist' approach to teaching and learning. This article attempts to flesh out these ideas by relating them to past and present practice, and sketches possible paths along which digital library training might evolve.
\end{abstract}

\section{Keywords}

Digital Library; Training; University Libraries; United Kingdom.

For anyone engaged in managing staff training in Higher Education libraries nowadays, the halcyon days of the traditional library seem like a period of lost certainties. When libraries consisted wholly of print collections, public service work (for example) presented an ideal combination of generic skill acquisition combined with the construction of a unique personal skill-set. If that sounds rather an abstract formulation, what follows presents specific examples of how this model worked, and contrasts it with present day scenarios.

\section{Traditional models}

The traditional model of reference librarianship and subject specialism in academic libraries often involved training the subject librarian to be at one level primarily a cataloguer. Having been trained in the generic skills of bibliographic description and indexing (above all, the Anglo American cataloguing rules), the novice subject specialist could apply these metadata skills to the real-life tasks of building a collection within a defined subject area. The subject reference librarian would catalogue all the relevant stock entering the academic library, thereby building a knowledge base of the contents of 'their' part of the library's collection. Subject librarians knew their stock because most of it had physically gone through their own hands.

In this sense, the generic skills of cataloguing became a means of constructing a personal world of knowledge. Traditional subject librarians rightly had a highly developed sense of the uniqueness of what they knew, yet they could build this unique knowledge base with skills that were widely shared and universally recognised. Moreover, the limited searchability of traditional card catalogues meant that the

This is a peer-reviewed author accepted manuscript of the following research article: 
personal knowledge of the subject specialist reference librarian was an unsurpassable guide to the content of a rich hard copy collection (Mackenna, 1977).

In terms of a training philosophy, this approach was wonderfully coherent and eminently manageable. The skills of bibliographic description were in abundant supply within the traditional academic library, meaning that there was a ready source of training expertise. And even if work-flow demands were such that in-house staff were unable to allocate sufficient time to the training of novice subject specialists, it was easy enough to buy in staff training from external sources. Given the consensus at the time on the nature of the generic skills needed by all librarians, a number of external organisations could offer induction and staff development to support an institution's training needs.

Although the advent of opacs and online database searching marked the first real incursions of digital library developments into this world, they only seemed to confirm the training ethos of the traditional library environment. Opacs were just computerised versions of card catalogues, so generic MARC manuals simply joined AACR manuals on the academic librarian's shelf (though the new breed of Systems Librarian seemed to speak a language all of their own). Online database searching simply required a new generic skill set, which, like the skills of cataloguing, were the same world wide. Searching Data Start, STN or Dialog meant learning a fairly consistent set of database interrogation commands, and again generic training was easily bought in from external organisations. Online searching was the same in Cambridge England as in Cambridge Massachusetts, just as AACR had always been.

\section{New skill-sets}

However, the first real signs of collapse in this model came with the advent of end user searching (dating in the UK from the advent of affordable cd-rom bibliograhic databases in the mid-1980s, and accelerated by the advent of BIDS at Bath in 1991), followed by Internet access via the World Wide Web (dating from 1993). Such developments paved the way for the present day proliferation of a multitude of competing external information services, all of which are accessible via the Internet to the library user outside of the physical space of the Library's print collection. (Duff, 2002)

From the point of view of subject specialism, the cacophony of competing interfaces simply reinforced the need for subject expertise. Whereas subject specialists had once had unique knowledge of their in-house library collection, they now needed a pretty good knowledge of the local collection, but this knowledge was probably acquired by use of the opac in reference work, rather than by cataloguing the stock itself. This cataloguing task gradually became the preserve of a small number of generalist cataloguers rather than a larger number of subject specialists (Heaney, 1991).

However, a crucial skill that now set the subject specialist apart was an impressive mastery of the many database interfaces that their library had bought in, with a particular focus on the subject databases that supported their user groups. And the complexity of such database interfaces meant that subject expertise was essential for the promotion of information literacy - demonstrating subject expertise at the

This is a peer-reviewed author accepted manuscript of the following research article:

Joint, N. (2003), "Staff development and training in the digital library environment", Library Review, Vol. 52 No. 9, pp. 417-421. https://doi.org/10.1108/00242530310501428 
reference interview was in many ways less important than acquiring and imparting some of this expertise to the end user. Being clever wasn't enough, passing the cleverness on was the new requirement.

\section{The decline of generic skills acquisition}

However, what seems to have passed into history is the certainty of a generic skill set shared by all subject librarians. Though the mysteries of Boolean logic have certain generic qualities, the highly differentiated nature of most digital library information products has removed much of the generic underpinning from subject specialism.

Where does this leave the manager of training programmes in the digital library environment? If each subject specialist has a unique skill-base, how can generic, library-wide in-house training programmes be promoted? Although the training materials provided for digital library users can be re-used as staff development materials, these materials are as highly specialised as the information products they describe, and they do not readily form the basis of a common staff training curriculum.

The same digital library problems occur in other aspects of public service work. Borrowing and return sections (those who stamp book and take fines) could once control library membership and entitlements internally, creating in turn a coherent training programme for new front of house staff - if someone wanted library membership and came into category $\mathrm{x}$, they could join for a certain period and could borrow y number of books. But now membership of and access to the digital library summed up in the UK by the question, 'Can I have access to this library's electronic services via Athens please?' - is a complex matrix of technical issues and legal entitlements most of which are controlled by non-library agents. Such agents comprise primarily database vendors with their heterogeneous and evolving licence agreements and the network security software of computing service or IT service departments. It is very hard to train staff in-house in matters that are not under inhouse control.

Expertise in these areas has now become a fluid continuum, a preserve of staff who spend much time tracking changing patterns of entitlements and network access arrangements. So this expertise no longer presents as a fixed quantity of static knowledge that can be poured into untrained staff as if they were empty vessels, devoid of knowledge. Staff cannot simply carry this knowledge around until the Library itself decides that it will change its access and entitlement arrangements, because the knowledge they need to do their jobs just isn't like that. Such knowledge is fluid and changing, and so it must be continually constructed through a constant self-directed learning experience, with staff to a significant extent becoming responsible for their own training. This is a challenging scenario for library managers.

\section{The Nurnberg Funnel}

Fortunately, we can turn to developments in the understanding of IT training and pedagogy in Higher Education to help us understand where we now are with staff training in the digital library. The preceding description of changing staff development patterns quite clearly echoes the thinking of writers such as John Carroll 
(1990), whose arguments against traditional instructional models for helping people learn how to use unfamiliar software packages are well known in modern teaching and learning circles. The common generic skill set of the traditional library was imparted rather like the materials poured down Carroll's Nurnberg funnel into the empty skulls of ignorant students. And it worked fine - systematic training in bibliographic description which requires "users to proceed step by step though sequences of drill and practice exercises" (Carroll, ibid., p. 5) was well suited to traditional librarianship, and has a valid role in training for the creation of metadata for digital library collections even now.

However, public service work - where libraries now buy in access to datasets and commercial digital library services with the metadata scheme already in place - is different. Rather than creating elaborate manuals for systematically teaching how these tools work, Carroll's advice would be to bypass heavy duty training tomes (there is no AACR for the digital library world) and get the untrained member of staff to do real tasks as soon as possible. Any materials that you do provide the untrained should simply support their own goal-directed activities.

Of course, this may make your staff feel like you are absolving yourself of the need to train them. In particular, they will make more mistakes by acquiring skills in this way, and may hold you, their trainer, to account, for these mistakes. The traditional library environment, where making a mistake in creating an accurate bibliographic description may have resulted in a valuable acquisition being irretrievably lost in a massive and complex catalogue, inevitably created a 'blame culture' in training where errors were reprehensible and to be avoided at all costs. We need to leave this training culture behind entirely and encourage risk in staff learning, so that the untrained will construct knowledge by making errors, recognising those errors, and evolving strategies for recovering from those errors. We need to bring mistakes into the open and encourage a process of learning by failure and recovery from failure. After all, we are not going to 'break' a database irrecoverably by searching it badly - unlike a traditional cataloguing error, which may irrecoverably consign an item to oblivion.

\section{Learning metaphors}

In particular, we need to re-think our metaphors for staff learning (rather than staff training) in the digital library world. For example, many have praised the European Computer Driving Licence scheme as an ideal training model and curriculum that could be imported into digital library skills acquisition (ECDL, 2000). In many ways this is true. However, we should think very carefully about this 'driving licence' metaphor for learning.

What is the overriding emotion of a novice driver faced with sole command of a car for the first time? It is fear. Fear of crashing the car, or fear of damaging someone else or themselves. If the most important feature of learning to use software is guided exploration of error possibilities (Horn, 2003), does the driving lesson metaphor really help us? In fact this learning metaphor comes up time and time again - one staff member in my own Library in fact told me 'I feel like I'm in sole charge of the Starship Enterprise when I have to help readers use the library's electronic databases'. This member of staff had independently created a metaphor of driving an

This is a peer-reviewed author accepted manuscript of the following research article: Joint, N. (2003), "Staff development and training in the digital library environment", Library Review, Vol. 52 No. 9, pp. 417-421. https://doi.org/10.1108/00242530310501428 
uncontrollable machine to describe their own learning experience in the digital library. I pointed out that the Library had experienced neither alien invasion nor ever crashed into another planet, and that the worst that could happen would be to look foolish in front of a reader. This for many of us is an experience we dread, but it is not the same as physical peril (although in highly conventional cultures such as British society, this tells us much about how social disgrace and embarrassment inhibit our ability to learn creatively).

We are clearly failing in our duties as trainers if we actually validate a metaphor of dread as a way of encouraging staff to learn in the digital library. Nevertheless it is very hard to disencumber ourselves from the negative aspects of traditional learning and training models as we endeavour to support our staff in their encounters with digital library challenges.

\section{Appraisal schemes}

Moving beyond metaphors for staff training, we also need to think about our models of appraisal and our systems for identifying training needs in the new library world. The traditional model of appraisal and training often works on a yearly or two yearly cycle, and gives an opportunity for managers to identify areas of staff performance staff which are less than optimal, identify consequent training needs from such examples of underperformance and then derive training programmes for staff which will address these training needs. The individual manager may be required to inform a central library training manager of the outcomes of this process, and the central training manager can aggregate common training needs to produce a library-wide training schedule for the next year or two. This avoids individual line managers setting up training inefficiently in an ad hoc, small-scale fashion, and helps library management maintain a total overview of the training needs in their department.

However, this model is increasingly at variance with the training and learning needs of staff in the digital library world. If staff skills are increasingly 'nucleated' and constructed by staff by themselves for themselves though time, it becomes much harder to create library-wide training programmes which will provide useful infusions of skills. As a result, appraisal may even become a process where appraisers struggle to find marginal areas of training need which can form the basis of generalisable training programmes. Appraisees then take such training as is offered and find it of dubious value when faced with the genuine ever-changing tasks in their real work. So staff become disenchanted.

Worse, appraisal may generate shopping lists of generic training from appraisees, training which becomes swiftly far less important than the subsequent person-specific training needs that crop up in the every day course of an individual's work. As a result, the highly individualised on the job training offered by genuinely effective line managers takes greater priority over appraisal-generated generic training. Generic training, once supplanted and de-prioritised as a result of the pressures of real work requirements, may (quite justifiably) never then take place. A new appraisal cycle starts, and the shopping list of training from the previous cycle seems to have been forgotten. And again, staff become disenchanted - why bother to appraise them and

This is a peer-reviewed author accepted manuscript of the following research article: 
list their training needs if these needs are going to be forgotten as other priorities come along?

\section{Constructivist appraisal?}

So we need to think about formalising the reality of staff learning in modern libraries in some way, shape or form. If staff are already learning to construct their own knowledge and skill-sets in order to fulfil task requirements, we should reinforce this success in some way.

A new more 'constructivist' approach can be envisaged (Emtech, 2003, provide a variety of WWW sources on constructivism). This form of staff appraisal might involve the role of the central library training officer being increasingly devolved down to line managers, whose ability to improvise on the job training for their staff on an 'as needed' basis would become a core part of their management role. Line managers would have to accept that they may not in fact know as much as their staff do about their tasks - unlike the past, where the well-established head of a group of subject librarians may have catalogued perhaps more of the stock in a library than anyone else, and will have certainly memorised the whereabouts of more of the stock in that library than anyone else.

If job knowledge is a linear and fluid process of construction, a good line manager could be one who sits down beside a struggling member of staff and shares the learning process with them, so that they learn to learn together. Once the learning process has been facilitated by the manager, the manager may then forget completely how to do that task - it's really up to the staff member to retain the knowledge for as long as they need it, and when the knowledge becomes out of date, they can construct a new solution to a new task, along the lines that their line manager has helped them discover. The success with which they did this could still be monitored and evaluated, so that 'appraisal outcomes' would still continue and be formally recorded in some fashion. But it is a different model from what we have in many libraries at the present time.

In reality, of course, practical training is more complex than such a stark and simple outline might lead us to believe. Many authors argue for a hybrid approach to any learning or training situation (Cronje, 2000). Indeed, if staff are to be expected to abandon training manuals and launch into self-directed learning with real tasks, what happens when that member of staff leaves and takes their 'constructivist skill set' with them? Their line manager would undoubtedly be down on their knees asking them to leave behind some sort of traditional manual with which they could train their imminent bewildered replacement.

However, there is clearly a need for a fresh approach to training in the digital library environment, and modern developments in teaching and learning theory may well have much to offer us as we try and address these staff development challenges. It is up to practitioners to take these theories on board, see whether they work in reality and then share this experience with their community of practice. Ultimately it is the practitioner who must make the final judgement, but this can only happen if such theories have been applied in the workplace, rather than rejected outright as

This is a peer-reviewed author accepted manuscript of the following research article:

Joint, N. (2003), "Staff development and training in the digital library environment", Library Review, Vol. 52 No. 9, pp. 417-421. https://doi.org/10.1108/00242530310501428 
something only for academics and those absorbed in educational research. There is in fact nothing so relevant to practice as learning theory, and the possibility of constructivist appraisal should indeed merit exploration at the level of practice.

\section{References}

Caroll, J. M. (1990) The Nurnberg Funnel: designing minimalist instruction for practical computer skill. MIT, Cambridge.

Cronje, J. (2000) Paradigms Lost: Towards Integrating Objectivism and Constructivism. ITFORUM PAPER \#48

$<$ http://it.coe.uga.edu/itforum/paper48/paper48.htm> (last visited 25th July 2003).

Duff (2002) Four "e" pochs: the story of informatization", Library Review Vol. 52 No. 2, pp. 58-64.

Emtech (2003) Constructivism, Instructivism, and Related Sites.

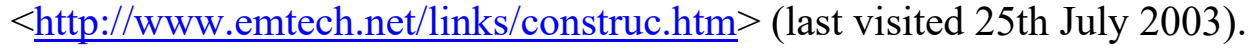

ECDL (2000). European Computer Driving Licence: the international pc skills standard. http://www.ecdl.co.uk/ (last visited 25th July 2003).

Heaney, H. (1991) "Subject-Divisional Organisation: The Standard Still Flies", Library Review, Vol. 40 No. 5, pp. 21-26.

Horn, R.E. (2003) Book review: The Nurnberg Funnel by John Carroll. http://www.stanford.edu/ rhorn/RvwOfNurnbrgFnnl.html (last visited 25th July 2003).

MacKenna, R.O. (1977) "Subject-divisional Organisation in a major Scottish Research Library" in: McAdams, F. (Ed.) Of One Accord: Essays in Honour of W.B. Paton, Scottish Library Association, Glasgow, pp. 99-109.

This is a peer-reviewed author accepted manuscript of the following research article:

Joint, N. (2003), "Staff development and training in the digital library environment", Library Review, Vol. 52 No. 9, pp. 417-421. https://doi.org/10.1108/00242530310501428 